\title{
ANALISIS PENGARUH FAKTOR BURNOUT SYNDROME: INDIVIDUAL EFFORT FACTORS, ORGANIZATIONALS EFFORT FACTORS, DAN WORK ENVIRONMENT EFFORT FACTORS TERHADAP JOB SATISFACTION PADA PERAWAT DI RSUD RATU ZALECHA MARTAPURA (MASA PANDEMI COVID-19)
}

\author{
Neisya Saliza Gifariani, Asruni, SE., MM \\ Sekolah Tinggi Ilmu Ekonomi Pancasetia Banjarmasin. \\ Jl. Ahmad Yani Km. 5.5 Banjarmasin \\ neisyalizag@gmail.com
}

\begin{abstract}
This study aims to determine both partially and simultaneously how much influence the Burnout Syndrome Factors: individual Effort Factors, Organizational Effort Factors, and Work Environment Effort Factors on the Job Statisfaction on Nurse at RSUD Ratu Zalecha Martapura (During Cvid-19 Pandemic). The method used in this study is a quantitative method and with a population of 140 (seventy three), a sample of 104 (one hundred and four) stratified random sampling was taken, the research instrument was validity and reliability tests, the data were tested using regression. multiple linear. The results of the study indicate that the Individual Effort Factor is the most dominant factor in increasing job satisfaction of officers. $R$ Square is 0.484 , which means that the variation in the contribution of all independent variables to the dependent variable is $48.4 \%$, while the remaining $51.6 \%$ is explained by other causes outside of this study.
\end{abstract}

Keyword : Burnout Syndrome, Individual Effort Factors, Organizational Effort Factors, Work Environtment Effort Factors, Job Statisfaction.

\begin{abstract}
Abstrak : Penelitian ini bertujuan untuk mengetahui baik secara parsial dan simultan seberapa besar Pengaruh Faktor Burnout Syndrome: individual Effort Factors, Organizational Effort Factors, dan Work Environtment Effort Factors terhadap Job Statisfaction Pada Perawat di RSUD Ratu Zalecha Martapura (Masa Pandemi Covid19). Metode yang digunakan dalam penelitian ini adalah metode kuantitatif dan dengan populasi sebanyak 140 (tujuh puluh tiga), diambil sampel dengan teknik stratified random sampling sebanyak 104 (seratus empat) orang, instrument penelitian uji validitas dan uji reliabilitas, data - data diuji dengan menggunakan regresi linear berganda. Hasil penelitian ini menunjukkan bahwa Hasil penelitian menyatakan bahwa Individual Effort Factor menjadi faktor yang paling dominan terhadap peningkatan kepuasan kerja perwat. R Square sebesar 0,484 yang berarti besarnya variasi sumbangan seluruh variabel bebas terhadap variabel terikatnya adalah $48,4 \%$ sedangkan sisanya $51.6 \%$ dijelaskan oleh sebab lain diluar dari penelitian ini.

Kata Kunci : Burnout Syndrome, Individual Effort Factors, Organizational Effort Factors, Work Environtment Effort Factors, Job Statisfaction.
\end{abstract}




\section{LatarBelakang}

Perawat merupakan salah satu tenaga kesehatan yang berjuang dalam menyelematkan pasien Covid-19 di rumah sakit dan juga berjuang dalam mencegah penularan infeksi Covid-19 di Puskesmas bersama tenaga kesehatan lainnya dan Satgas Covid-19. Berdasarkan laporan Satgas Covid-19 DPP PPNI, hingga 16 Mei 2020, jumlah perawat yang terinfeksi Covid-19 sebanyak 59 orang, dan telah gugur sebanyak 19 orang $(3,2 \%)$.

Stressor tinggi yang sering dialami oleh perawat sebagai kondisi dalam upaya penyelamatan pasien, mengerjakan rutinitas, ruang kerja yang sumpek, jumlah pasien yang banyak, dan harus bertindak cepat dalam menangani kebutuhan pasien. Perawat tidak mampu beradaptasi pada situasi dengan tekanan kerja tinggi dan berlangsung terus menerus dalam intensitas tinggi, maka inilah yang disebut dengan burnout (Tawale \& Novita, 2011). Perawat profesional sangat beresiko mengalami burnout karena terus dituntut untuk memberikan pelayanan yang paripurna kepada pasien.

Di Indonesia belum banyak studi yang menggambarkan tentang kejadian burnout pada perawat di rumah sakit. Penelitian yang dilakukan oleh Khotimah (2010) di Rumah Sakit Pekalongan menunjukkan bahwa insiden burnout pada perawat sebesar $65,9 \%$ yang ditentukan oleh lingkungan kerja, psikologis, sedangkan sisanya ditentukan oleh faktor lain. Permasalahan burnout juga ditemukan peneliti di RSUD Ratu Zalecha Martapura. Konsekuensi yang ditimbulkan dari burnout syndrome adalah turnover dan penurunan kinerja sehingga outcome kepada pasien juga buruk (Schaufeli et al., 2009). Edelwich \& Brodsky (1980) berpendapat bahwa turnover merupakan hasil akhir dari tahapan yang ada di dalam proses burnout syndrome

Variabel individual effort dan organizational effort diharapkan mampu menurunkan burnout syndrome yang dialami oleh perawat sehingga mampu meningkatkan kepuasan kerja pada perawat. Berdasarkan latar belakang tersebut, peneliti merasa perlu melakukan penelitian yang berjudul "Analisis Pengaruh Faktor Burnout Syndrome: Individual Effort Factors, Organizational Effort Factors, dan Environtmen Effort Factors terhadap Job Statisfaction Pada Perwat di RSUD Ratu Zalecha Martapura (Masa Pandemi COVID-19").

\section{Studi Literatur}

Burnout syndrome merupakan proses yang terus berkembang dari waktu ke waktu. Berbeda dengan teori yang dikemukakan oleh Freudenberger. Burnout syndrome merupakan suatu proses dimana terjadi suatu perubahan perilaku negatif sebagai respon terhadap tekanan dan stress pekerjaan dalam waktu yang berkepanjangan. Seseorang yang mengalami burnout syndrome akan menjadi kehilangan semangat atau putus asa, pesimis, melakukan kesalahan dalam pekerjaan, apatis, mudah marah kepada pasien atau rekan kerja, tidak mau menerima perubahan dan kehilangan kreativitas.

Burnout syndrome berbeda dengan stress (Cherniss, 1980). Karyawan yang mengalami burnout syndrome akan merasa kehilangan motivasi dan putus asa, sedangkan ketika seseorang mengalami stress maka cenderung bertindak emosional secara berlebihan (Porter, 2007). Stress berkepanjangan dapat berpotensi menjadi burnout syndrome, sedangkan kondisi burnout syndrome yang dialami oleh seseorang belum tentu disebabkan oleh stress.

Burnout syndrome telah menjadi fenomena psikologis yang cenderung bekerja melawan peningkatan kinerja seseorang, efektivitas dan keluaran organisasi. Pekerjaan yang penuh tekanan membutuhkan upaya individu dan organisasi untuk mengatasi burnot syndrome. Dukungan manajerial mampu mengurangi efek stres kerja dan kelelahan serta komitmen kerja, kepuasan pekerja di tempat kerja. Bektas (2013) menyebutkan 
individual effort factor dan organizational effort factor merupakan faktor yang mempengaruhi burnout syndrome.

Burnout syndrome dipengaruhi oleh faktor-faktor yang terdapat dalam organisasi dan individu, sesuai dalam bahwa burnout syndrome dipengaruhi oleh faktor dari organisasi atau lingkungan kerja itu sendiri dan faktor personal atau individu. Faktor-faktor tersebut dapat diidentifikasi sebagai faktor intrinsik dan ekstrinsik. Upaya individu merupakan faktor intrinsik. Upaya organisasi merupakan faktor ekstrinsik. Bila faktor ini digabungkan maka akan mendapatkan kelengkapan. Jika faktor ini dikombinasikan dan digunakan secara efektif, dapat mengatasi burnout syndrome dalam kehidupan kerja

Job satisfaction atau kepuasan kerja merupakan perasaan seseorang terhadap pekerjaannya. Kepuasan kerja sebagai melakukan perbandingan yang dilakukan oleh karyawan untuk mencapai serta memelihara kesesuaian antara diri dan lingkungan mereka (Weiss et al., 2007). Definisi ini telah mendapat dukungan yang menjelaskan bahwa kepuasan kerja sebagai perasaan seseorang pegawai mengenai pekerjaannya. Job satisfaction dapat diartikan sebagai apa yang membuat orang-orang menginginkan dan menyenangi pekerjaan.

Faktor - faktor yang mempengaruhi kepuasan kerja sebagai berikut (Gilmer, 1969) . Kesempatan untuk maju, keamanan kerja, gaji, manajemen kerja, kondisi kerja, komunikasi, dan fasilitas pekerjaan.

Coronavirus disease tahun 2019 atau Covid19 adalah jenis baru dari Coronavirus, selain memberikan dampak fisik dapat juga memiliki efek serius pada kesehatan mental seseorang (Huang and Zhao, 2020; Salari, Hosseinian-Far, Jalali, Vaisi-Raygani, Rasoulpoor, Mohammadi, Rasoulpoor and Khaledi-Paveh, 2020). Berbagai gangguan psikologis telah dilaporkan dan dipublikasi selama wabah Covid-19 di Cina, baik pada tingkat individu, komunitas, nasional, dan internasional. Pada tingkat individu, orang lebih cenderung mengalami takut tertular dan mengalami gejala berat atau sekarat, merasa tidak berdaya, dan menjadi stereotip terhadap orang lain. Pandemi bahkan menyebabkan krisis psikologis (Xiang, Li, Zhang, Qinge Cheung, and Chee H, 2020). Identifikasi individu pada tahap awal gangguan psikologis membuat strategi intervensi lebih efektif.

\section{Metode Penelitian}

Penelitian dilaksanakan di RSUD Ratu Zalecha Martapura dengan waktu penelitian kurang lebih 1 bulan. Metode yang digunakan dalam penelitian ini adalah metode kuantitatif dan dengan populasi sebanyak 140 (tujuh puluh tiga), diambil sampel dengan teknik stratified random sampling sebanyak 104 (seratus empat) orang. Instrument penelitian uji validitas dan uji reliabilitas, data - data diuji dengan menggunakan regresi linear berganda. Alat yang digunakan dalam penelitian ini adalah kuesioner, wawancara dan dokuemntasi.

Variabel penelitian meliputi Individual Effort Factors (Independent Variabel (X1)) Organizational Effort Factors (Independent Variabel (X2)), Work Environment Effort Factors (Independent Variabel (X3)), dan Job Statisfaction (Dependent Variabel (Y1)). Jenis data yang digunkan dalam penelitian ini adalah data kuantitatif yang meliputi sumber data primer. Sumber data primer yang berasal dari data asli ataupun yang diperoleh langsung dari lapangan dengan menyebar kuesioner.

\section{Hasil Penelitian dan Pembahasan}

Pengaruh Secara Simultan faktor Burnout Syndrome: Individual Effort Factors, Organizational Effort Factors, dan Environtmen Effort Factors terhadap Job Satisfaction

Hasil penelitian menujukkan bahwa terdapat pengaruh yang signifikan antara Individual Effort Factors Organizational Effort Factors, dan Environtmen Effort Factors secara simultan atau bersama-sama terhadap Job Satisfaction pada perawat di RSUD Ratu 
Zalecha Martapura. Dari analisis regresi berganda yang diperoleh dari nilai Sig. adalah sebesar 0,000 yang kurang dari 0,05 , maka sesuai dengan dasar pengambilan keputusan dalam uji $\mathrm{F}$ dapat disimpulkan bahwa hipotesis diterima. Hal ini berarti besarnya pengaruh faktor individu, organisasi dan lingkungan terhadap kepuasan kerja perawat 50,4\%

Berdasarkan hasil penelitian diketahui bahwa fator Burnout Syndrome berpengaruh terhadap Kepuasan Kerja. Pengaruh kedua variabel tersebut adalah pengaruh negatif yang artinya semakin tinggi burnout syndrome maka akan semakin menurunkan kepuasan kerja. Namun, semakin rendah burnout syndrome maka akan meningkatkan kepuasan kerja perawat di RSUD Ratu Zalecha Martapura.

Pengruh Secara Parsial faktor Burnout Syndrome: Individual Effort Factors, Organizational Effort Factors, dan Environtmen Effort Factors terhadap Job Satisfaction

- Pengaruh Individual Effort Factors terhadap Job Satisfaction

Berdasarkan hasil penelitian diketahui bahwa Individual Effort Factors berpengaruh terhadap Kepuasan Kerja. Pengaruh kedua variabel tersebut adalah pengaruh positif yang artinya semakin meningkat Individual Effort Factors maka akan semakin meningkatkan kepuasan kerja, namun peningkatan tersebut cukup signifikan. Hal ini menunjukkan bahwa job satisfaction atau kepuasan kerja yang dirasakan oleh perawat akan dapat terbentuk melalui adanya usaha yang dilakukan oleh seorang perawat dalam menjalankan tugasnya

- Pengaruh Organizational Effort Factors terhadap Job Satisfaction

Berdasarkan hasil penelitian diketahui bahwa Organizational Effort Factors berpengaruh terhadap Kepuasan Kerja. Pengaruh kedua variabel tersebut adalah pengaruh positif, artinya semakin baik upaya organisasi maka akan semakin meningkatkan kepuasan kerja perawat. Hasil penelitian ini membuktikan bahwa variabel organizational effort factors berpengaruh terhadap kepuasan kerja, menunjukkan bahwa job satisfaction atau kepuasan kerja yang dirasakan oleh perawat dapat terbentuk dengan baik melalui berbagai usaha. Usaha yang telah diterapkan oleh RSUD Ratu Zalecha Martapura dalam organisasi seperti dukungan pimpinan, dukungan rekan kerja dan atmosfer organisasi.

- Pengaruh Work Environment terhadap Job Satisfaction

Berdasarkan hasil penelitian diketahui bahwa Work Environment berpengaruh terhadap Kepuasan Kerja. Pengaruh kedua variabel tersebut adalah pengaruh positif yang artinya semakin tinggi work environment maka akan semakin meningkatkan job satisfaction. Adanya temuan yang membuktikan bahwa variabel work environment berpengaruh terhadap kepuasan kerja menunjukkan bahwa semakin baik lingkungan kerja yang tercipta di RSUD Ratu Zalecha Martapura maka akan semakin tinggi kepuasan kerja yang dirasakan perawat.

Pengaruh Paling Dominan dari faktor Burnout Syndrome: Individual Effort Factors, Organizational Effort Factors, dan Environtmen Effort Factors terhadap Job Satisfaction

Dari hasil penelitian yang diapatkan Individual Effort Factor atau pengaruh dari dalam diri perawat itu sendiri menunjukkan bahwa berpengaruh paling dominan terhadap kepuasan kerja. Hal ini didapatkan dari hasil uji regresi yang diabil dari angka koefisian beta, yang menunjukkan nilai dari variabel individual effort factors berada diangka 0,631 paing tinggi diantara variabel lainnya. Maka dapat diartikan variabel yang paling dominan untuk mempengaruhi kepuasan kerja perawat adalah faktor individu. 


\section{Kesimpulan}

Berdasarkan analisis yang telah dialakukan dapat diambil beberapa kesimpulan antara lain:

1. Individual Effort Factors, Organizational Effort Factors, dan Work Environment berpengaruh secarajob simultan atau terdapat pengaruh yang signifikan bersamasama terhadap Job Statisfaction

2. Individual Effort Factors, Organizational Effort Factors, dan Work Environment berpengaruh secara parsial atau terdapat pengaruh yang signifikan masing-masing variabel terhadap Job Statisfaction

3. Individual Effort Factor menjadi faktor yang paling dominan terhadap peningkatan kepuasan kerja perwat.

\section{DaftarPustaka}

Campayo, G.J., Puebla-Guedea, M., Herrera-Mercadal, P., \& Daudén, E. (2016). Burnout syndrome and demotivation among health care personnel. managing stressful situations: the importance of teamwork. Actas Dermo- Sifiliográficas (English Edition), 107(5), 400-406.

Malaquin, S., Mahjoub, Yazine., Musi, Ariana., Zoghieb, Elie., Salomon., Guibarlt, M., Dupont,H. (2016). Burnout syndrome in critical care team members: A monocentric cross sectional survey. Anaesth Critical Care PainMed: 36, 223-228.

Nwafor, C.E., Immanel, E.U., ObiNwosu, Harry. (2015). Does nurses' self- concept mediate the relationship between job satisfaction and burnout among Nigerian nurses. international Journal of Africa Nursing Sciences, 3(2015) 71-75.

Schaufeli, W. B., \& Greenglass, E. R. (2001). Introduction to special issue on burnout and health. Psychology \& health, 16(5), 501- 510

Schaufeli, W. B., \& Greenglass, E. R. (2001). Introduction to special issue on burnout and health. Psychology \& health, 16(5), 501- 510.

Swansburg, R. C., \& Swansburg, R. J. (1999). Introductory management and leadership for nurses: an interactive text. Jones \& Bartlett Pub

Tawale dan Novita, E.(2011). Hubungan antara Motivasi Kerja Perawat dengan Kecenderungan mengalami Burnout pada perawat. INSAN, 13(02), 74-84.

Wexley, K. N., \& Yukl, G. A. (1977). Organizational Behavior and PersonnelPsychology. Illinois: Richard D. Irwin.

Zhang, L. F., You, L. M., Liu, K., Zheng, J., Fang, J. B., Lu, M. M., Lv, Ai. L., Ma, W. G., Wang, J., Wang, S. H., Wu, X., Zhu, X. W., \& Bu, X. Q. (2014). The Association of Chinese Hospital Work Environtment with Nurse Burnout, Job Satisfaction and Intention to Leave. Nursing Outlook, 62, 128- 137. 